DOI: $10.21105 /$ joss.00424

\section{Software}

- Review ¿

- Repository u

- Archive cu

\section{Licence}

Authors of JOSS papers retain copyright and release the work under a Creative Commons Attribution 4.0 International License (CC-BY).

\title{
Quail: A Python toolbox for analyzing and plotting free recall data
}

\section{Andrew C. Heusser ${ }^{1}$, Paxton C. Fitzpatrick ${ }^{1}$, Campbell E. Field ${ }^{1}$, Kirsten Ziman ${ }^{1}$, and Jeremy R. Manning ${ }^{1}$}

1 Department of Psychological and Brain Sciences, Dartmouth College

\section{Summary}

Quail is a Python package for analyzing and plotting behavioral data from memory experiments. The current focus is on free recall experiments (Kahana 2012; Manning, Norman, and Kahana 2015). Quail implements classic and more recently developed memory analyses and provides easy plotting functions by wrapping Seaborn (Waskom et al. 2016). API documentation, tutorials and examples can be found on our readthedocs page [link]. Key features include:

- Creating and plotting serial position curves (probability of recalling items presented at each presentation position) (Ebbinghaus 1913; Murdock 1962)

- Creating and plotting probability of $N$ th recall curves- probability of recalling items at each presentation position as the $N$ th recall in the recall sequence (Hogan 1975)

- Creating and plotting lag-Conditional Response Probability curves- the probability of transitioning between items in the recall sequence, as a function of their relative presentation positions (Kahana 1996)

- Computing clustering metrics- i.e. single-number summaries of how often participants transition from recalling a word to another related word, where "related" can be user-defined (Kahana 2012; Manning, Norman, and Kahana 2015)

- Many nice additional plotting functions

- Convenience functions for loading and saving data

- Wrapper functions for automatically transcribing speech data (audio files) using the Google Cloud Speech-to-Text API

Our toolbox is primarily aimed at memory researchers who want to analyze and visualize free recall data.

The toolbox name is inspired by Douglas Quail, the main character from the Philip K. Dick short story We Can Remember It for You Wholesale (the inspiration for the film Total Recall).

\section{References}

Ebbinghaus, H. 1913. On Memory: A Contribution to Experimental Psychology. New York.

Hogan, R. M. 1975. "Interitem Encoding and Directed Search in Free Recall." MC 3: 197-209. doi:10.3758/BF03212898.

Kahana, M. J. 1996. "Associative Retrieval Processes in Free Recall." Memory \& Cogni- 
tion 24. doi:10.3758/BF03197276.

2012. Foundations of Human Memory. Oxford University Press. New York, NY.

Manning, J. R., K. A. Norman, and M. J. Kahana. 2015. "The Role of Context in Episodic Memory." In The Cognitive Neurosciences, Fifth Edition, edited by M. Gazzaniga, 557-66. MIT Press.

Murdock, B. B. 1962. "The Serial Position Effect of Free Recall." Journal of Experimental Psychology 64: 482-88. doi:10.1037/h0045106.

Waskom, M., O. Botvinnik, D. O'Kane, P. Hobson, S. Lukauskas, D. C. Gemperline, T. Augspurger, et al. 2016. "Seaborn: V0.7.1." doi:10.5281/zenodo.54844. 